\title{
MENINGKATKAN MOTIVASI BELAJAR DENGAN BERMAIN KARTU PADA PROGRAM KEAKSARAAN DASAR
}

\author{
Oleh : Ni Kadek Ayu Rinawati \\ PKBM Dharma Sedana Santhi, Kabupaten Karangasem, Provinsi Bali \\ ayurinawati123@gmail.com
}

\begin{abstract}
Abstrak: Pendidikan non-formal adalah layanan pendidikan maysarakat yang difungsikan sebagai pengganti, penambah, dan pelengkap pendidikan formal dalam rangka mendukung program pendidikan sepanjang hayat (life long education) oleh pemerintah. Pendidikan keaksaraan dasar merupakan program yang bertujuan untuk memfasilitasi masyarakat yang buta aksara agar memiliki kecakapan literasi dasar yakni, membaca, menulis, berhitung dan mampu berbahasa Indonesia. Selain itu, tujuan utama program pendidikan keaksaraan dasar adalah wadah bagi masyarakat dalam mengembangkan keterampilan dan pengetahuan serta membelajarkan warga belajar untuk memanfaatkan sumber daya alam sekitar guna meningkatkan taraf hidupnya. Penelitian ini bertujuan untuk mengetahui motivasi belajar warga belajar keaksaraan fungsional dalam belajar mengenal angka dengan bermain kartu angka. Penelitian ini menggunakan metode deskriptif kualitatif dengan teknik observasi dan wawancara. Objek penelitian ini adalah 1 orang tutor dan 10 orang warga belajar program keaksaraan dasar di PKBM (Pusat Kegiatan Belajar Masyarakat) Dharma Sedana Santhi yang terletak di Provinsi Bali. Hasil dari penelitian ini menunjukkan bahwa dengan bermain kartu dalam belajar angka mampu menumbuhkan motivasi belajar warga belajar. Proses belajar mengajar menjadi lebih menarik, menyenangkan dan memudahkan warga belajar untuk memahami materi yang disampaikan oleh tutor. Selain itu, warga belajar mampu bekerjasama dalam kelompok dalam menyelesaikan instruksi kelompok.
\end{abstract}

Kata-kata kunci: motivasi belajar, warga belajar keaksaraan fungsional, bermain kartu.

\section{IMPROVING LEARNERS' LEARNING MOTIVATION THROUGH NUMBERS CARD IN BASE LITERACY PROGRAM}

Abstract: Non-formal education is community education services that purposes to alternate, to add and to complete formal education in order to support life long education program. Base literacy program is a program which aims to facilitate illiterate community to possess base literacy skill, namely: reading, writing, able to calculating numbers and able to speak with national language, that is Bahasa Indonesia. Moreover, the main purpose of this program is to accommodate illiterate community in expanding their knowledge and skill as well as accustom them to utilize natural resources from the surroundings for their 
life. This study aimed to analyze learners' motivation with learning strategy, namely numbers card. This study is investigated by using descriptive qualitative method. The object of the study is 1 instructor and 10 learners in PKBM (Pusat Kegiatan Belajar Masyarakat) Dharma Sedana Santhi which is located in Province of Bali. The result shows that learners motivate to learn number or numerical due to numbers card uses in the learning process. The learning athmosphere becomes more interesting, fun and easier for learners to understand the material. Furthermore, learners could work collaboratively to solve a problem in group.

Keywords: learning motivation, base literacy program, numbers card.

\section{PENDAHULUAN}

Pendidikan merupakan hak dasar bagi setiap warga Negara dalam memperoleh kesempatan yang sama pada akses pendidikan, meningkatkan wawasan dan pengetahuan (Sujatmoko, 2010). Pendidikan merupakan upaya untuk mencapai kemerdekaan, pembebasan dan kesetaraan bagi setiap individu maupun kelompok yang terlibat dalam pendidikan.

Pendidikan secara umum dapat diselenggarakan melalui tiga jalur pendidikan, yakni pendidikan formal, informal dan non-formal. Undangundang No 20 Tahun 2003 menyebutkan bahwa pendidikan nonformal diselenggarakan bagi warga masyarakat yang memerlukan layanan pendidikan yang berfungsi sebagai pengganti, penambah, dan pelengkap pendidikan formal dalam rangka mendukung pendidikan sepanjang hayat (life long education).

Tugas pendidikan nonformal adalah membelajarkan warga masyarakat agar memiliki dan mampu mengembangkan keterampilan, pengetahuan, sikap, nilai-nilai, aspirasi untuk mengantisipasi kemungkinan perubahan di masa depan. Fungsi lainnya juga membelajarkan warga masyarakat agar mampu meningkatkan dan memanfaatkan sumber daya alam guna meningkatkan taraf hidupnya (Yulianingsih \& Pd, 2014)

\section{Konsep Pendidikan Keaksaraan Dasar}

Pendidikan keaksaraan dasar adalah program pendidikan non-formal yang diperuntukkan bagi warga masyarakat yang belum memiliki kecapakan literasi dasar. Yang mencakup keterampilan dasar literasi yakni membaca, menulis, menghitung (calistung) dan kemampuan berbahasa Indonesia , atau dalam kata lain belum melek aksara. Kemudian, mampu memanfaatkan kemampuan literasinya dalam kehidupan sehari-hari. Kusnadi dalam (Apriani \& Prakoso, 2019) mengatakan bahwa, di dalam setiap masyarakat, keaksaraan merupakan keterampilan yang diperlukan pada dirinya dan salah satu pondasi bagi keterampilanketerampilan yang lain.

Program pendidikan keaksaraan dasar ini merupakan perwujudan dari suatu kebijakan sosial dalam bentuk pelayanan sosial dalam bidang pendidikan (Apriani \& Prakoso, 2019). Sasaran program ini adalah warga masyarakat usia produktif (15-59 tahun). 
Selain itu, program ini juga bertujuan untuk membantu warga belajarnya untuk meningkatkan produktivitas, baik secara perorangan maupun kelompok sehinggga diharapkan dapat memiliki mata pencaharian dan penghasilan dalam rangka peningkatan taraf hidupnya. Tujuan mendasar program keaksaraan dasar adalah mengajarkan keterampilan ekonomi, baca dan tulis secara bersamaan dari awal yang merupakan bagian dasar dari fungsional aksara (Wulandari, 2018).

Dalam penyelenggaraan program ini, pemerintah bersinergi dengan Pusat Kegiatan Belajar Masyarakat (PKBM) sebagai eksekutor lapangan yang terjun langsung di masyarakat untuk mengelola program keaksaraan dasar ini. Proses pembelajaran warga belajar dengan tutor menjadi proses inti dari program ini. Pembelajaran adalah proses interaksi warga belajar dan tutor sebagai sumber belajar pada suatu lingkungan belajar.

Pembelajaran adalah satu pengalaman peribadi, melibatkan proses yang hanya dapat diperhatikan oleh orang lain melalui beberapa perubahan yang berlaku seumur hidup, dengan berbagai cara, dan konteks belajar yang berbeda.

Bagan 1. Model Penyelenggaran Program Keaksaraan Fungsional, diadaptasi dari Syukri (2008)

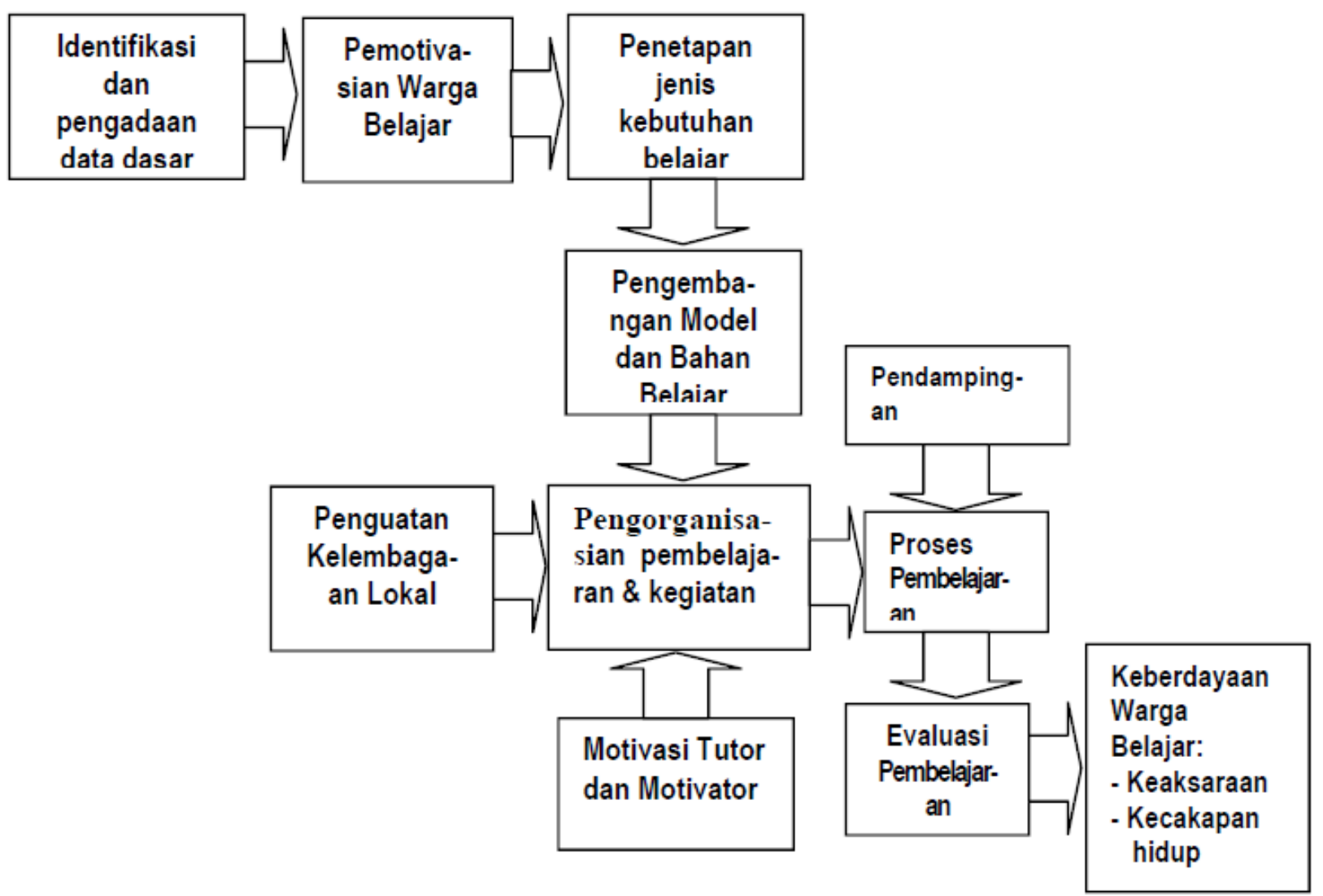

Sebagai pengatur proses pembelajaran (class facilitator), banyak hal yang tentunya harus tutor ketahui dan persiapkan. Sehingga proses pembelajaran tersebut dapat berjalan lancar dan dapat menghantarkan warga belajarnya mencapai tujuan pembelajaran yang diinginkan.
Dalam pembelajaran keaksaraan dasar, ada beberapa tantangan yang tutor hadapi. Pertama, di dalam satu rombongan belajar yang terdiri dari 10 orang warga belajar, usia warga belajar beragam antara usia 15-59 tahun. Kedua, untuk memfasilitasi kegiatan belajar mengajar yang 
efektif untuk usia yang beragam dan tergolong dewasa, tentunya diperlukan kecakapan dalam menentukan strategi pembelajaran agar semua warga belajar mampu mengikuti alur pembelajaran dengan baik sehingga hasil yang diharapkan dapat tercapai.

Tutor hendaknya mengetahui strategi yang cocok untuk diterapkan melalui faktor-faktor yang mempengaruhi kegiatan belajar mengajar warga belajar keaksaraan fungsional dengan usia yang beragam tersebut. Sadid (2019) mengungkapkan bahwa strategi pembelajaran harus disinkronkan dengan pengetahuan tutor terhadap karakteristik warga belajar.

Secara umum, ada dua faktor utama yang mempengaruhi hasil belajar warga belajar yaitu faktor internal (subjek belajar) dan eksternal (media dan lingkungan belajar) (Emda, 2018; King, 2019; Vibulphol, 2016). Kedua faktor jenis tersebut digunakan tutor sebagai acuan untuk memilih strategi pembelajaran yang tepat yang disesuaikan dengan kebutuhan dan karakteristik warga belajar.

Faktor eksternal meliputi faktor luar yang mempengaruhi proses belajar seperti lingkungan belajar, keluarga, ekonomi, guru, media belajar serta metode belajar yang digunakan (Hayes, 2016; Hapnita, 2018). Sedangkan faktor internal meliputi intelegensi, minat, bakat, motivasi, kesiapan belajar dan perhatian belajar Sheared (2010) pada (Abiddin et al., 2015).

Dalam konteks keaksaraan fungsional, menurut (Rochman et al., 2017) menyebutkan bahwa faktor internal yang berasal dari dalam diri warga belajar, meliputi: motivasi, pekerjaan, dan usia, warga belajar. Sementara, faktor eksternal ialah jarak tempat pembelajaran dengan rumah warga belajar dan metode pembelajaran yang digunakan selama pelaksanaan pembelajaran.

Faktor internal yaitu motivasi dan penguatan (reinforcement) harus difokuskan oleh tutor karena sangat berpengaruh terhadap keberhasilan pembelajaran warga belajar. Motivasi belajar adalah salah satu faktor penting yang perlu dipertimbangkan dalam segala kegiatan pembelajaran (Andriani \& Rasto, 2019; Emda, 2018; Lai \& Ting, 2013; Sing et al., 2016; Zuniarti \& Siswanto, 2013).

Penelitian dari (Saputra et al., 2018) menunjukkan motivasi belajar mempunyai hubungan yang positif dan signifikan dengan hasil belajar. Jika warga belajar sudah memiliki kertertarikan dan termotivasi pada suatu proses pembelajaran, maka materi yang diberikan oleh tutor akan mudah dipahami. Inovasi dalam pembelajaran, misalnya dengan penggunaan media pembelajaran sangat mutlak diperlukan dan diterapkan oleh semua tutor sehingga proses pembelajaran akan hidup dan lebih bermakna.

Beberapa penelitian yang telah dilakukan sebelumnya menunjukkan adanya pengaruh yang signifikan dalam penggunaan alat peraga kartu angka sebagai alat belajar yang inovatif yang mampu merangsang ketertarikan siswa dalam belajar (Annisa \& Dwi, 2019; Mulyasni, 2016; Nurfitriyanti \& Lestari, 2016; Pertiwi, 2019)66 dan thitung $\geq$ ttabel yaitu 48,66 $\geq 1,68$ sehingga $\mathrm{H} 0$ ditolak yang artinya $\mathrm{H} 1$ diterima. Adapun hasil observasi pada pertemuan I menunjukkan bahwa siswa masih kurang memperhatikan penjelasan guru tentang materi, siswa masih melakukan kecurangan pada permainan math games seperti mencabut kartu sebanyak dua kali, masih salah berhitung dalam bermain yaitu disebabkan karena masih kurangnya kemampuan siswa dalam berhitung sehingga menyebabkannya kesulitan dalam menurunkan kartu remi saat gilirannya memberikan kartu dan membutuhkan waktu yang cukup lama dalam bermain (lembar observasi terlampir.

Dilihat dari usia warga belajar keaksaraan dasar yang beragam dan dominan dewasa, maka pendekatan pembelajaran orang dewasa 
(andragogi) diperlukan dalam program ini (Waspodo, 2009). Menurut (Suhud, 2005) technology, art, and so forth have brought positive impacts for human life changes and progress in one hand. In other hand, however, they also results in human backwardness and marginality from their own life progress. Many people do not have access to the life progress since they are not ready in some aspects such as mentality, attitude and skills. Such reality leads people to develop their selves if they are to have deep insight, mentality for development, positive attitudes, and adequate skills. Community development is a process or action conducted to enhance human dignity and human resources quality. Andragogy approach in community development offers the necessity of learning approach to enhance people's insight, attitudes and skills. The activity is performed by: firstly, using assumption about changes that: (a pembelajaran andragogi memiliki lima karakteristik. Pertama, orang dewasa memiliki konsep diri sebagai pribadi yang mandiri, yang memandang dirinya sudah mampu sepenuhnya mengatur dirinya sendiri. Kedua, orang dewasa sudah memiliki pengalaman hidup yang cenderung berbeda sebagai akibat dari latar belakang kehidupannya. Ketiga, orang dewasa memiliki kesiapan tertentu sesuai dengan peran sosialnya untuk belajar. Keempat, orang dewasa cenderung untuk mempunyai pandangan bahwa apa yang mereka pelajari harus aplikatif untuk hidupnya. Kelima, bagi orang dewasa belajar adalah suatu proses dari dalam (bukan ditentukan kekuatan-kekuatan dari luar).

Semua asumsi tersebut membawa implikasi yang sangat penting untuk diperhatikan dalam upaya pembelajaran orang dewasa yang cenderung sangat berkaitan dengan motivasi serta menciptakan pembelajaran yang aplikatif untuk warga belajar itu sendiri. Solfema (2013) dalam (Yuse et al., 2018) menyampaikan bahwa orientasi pembelajaran orang dewasa, seorang tutor hanya sebagai fasilitator bukan bertindak sebagai seorang guru, melainkan sebagai seorang pembimbing dan memberikan bantuan kepada warga belajar.

Dengan latar belakang diatas, penulis menulis artikel yang berjudul "Meningkatkan Motivasi Belajar Dengan Bermain Kartu: Pada Program Pendidikan Keaksaraan Dasar". Tujuan dari penelitian ini yakni mengkaji manfaat penggunaan media kartu angka pada konteks pembelajaran keaksaraan fungsional yang mana warga belajarnya beragam usia. Kemudian, untuk mengetahui hasil belajar warga belajar keaksaraan fungsional dalam mengenal angka dengan menggunakan permainan kartu angka (card numbers). Serta untuk mengetahui bagaimana motivasi belajar warga belajar dalam proses pembelajaran dengan penggunaan media kartu angka (card numbers).

\section{METODE PENELITIAN}

Metode yang digunakan dalam penelitian ini yakni metodekualitatifdeskriptif. (Creswell \& Poth, 2013) menyatakan metode kualitatif bertujuan untuk memecahkan suatu masalah, menganalisa, mendeskripsikan, menginterpretasikan dan mengembangkan pemahaman yang mendalam terkait masalah yang ingin diteliti dalam bentuk kata-kata. Penelitian kualitatif dengan pendekatan deskriptif memerlukan keterangan langsung dari narasumber tentang keadaan objek penelitian yang akan diteliti. Sehingga peneliti memperoleh informasi atau gambaran terkait motivasi warga belajar keaksaraan fungsional dalam belajar angka dengan bermain kartu.

Subjek penelitian ini berjumlah 11 orang, yang terdiri dari 1 orang tutor dan 10 orang warga belajar di PKBM Dharma Sedana Santhi yang terletak di Provinsi Bali.

Teknik pengumpulan data dalam penelitian ini yakni dengan observasi dan interview. Pada teknik observasi, peneliti menggunakan observasi 
partisipatif untuk mengumpulkan data yang berkenaan dengan kegiatan pembelajaran pada satu kelompok belajar keaksaraan fungsional tersebut. Peneliti mengamati dan melihat secara langsung bagaimana pelaksanaan kegiatan pembelajaran keaksaraan fungsional pada satu kelompok belajar serta langsung menganalisis kejadian yang sedang berlangsung. Observasi ini dilakukan selama 3 jam pelajaran dari sesi awal pembelajaran, inti proses pembelajaran dan sesi akhir pembelajaran.

Teknik pengumpulan data pendukung pada penelitian melalui wawancara yang dilakukan untuk pengumpulan data dengan cara melakukan tanya-jawab secara langsung antara peneliti dengan sumber data. Sebagai perwakilan dari warga belajar lainnya, wawancara melibatkan 4 orang warga belajar (2 warga belajar laki-laki dan 2 warga belajar perempuan) dan 1 orang tutor.

Jenis wawancara yang digunakan adalah wawancara terstruktur dan mendalam dengan menggunakan daftar pertanyaan yang telah dipersiapkan sebelumnya. Tujuan dari wawancara ini untuk mendapatkan informasi yang mendalam terkait bagaimana motivasi warga belajar didalam belajar mengenal angka dengan bermain kartu angka (card numbers).

Tabel 1. Pedoman Wawancara

Wawancara tutor:

\begin{tabular}{|c|}
\hline $\begin{array}{l}\text { 1. Apa saja manfaat dari permainan kartu dalam } \\
\text { mengenal angka yang sekaligus memotivasi warga } \\
\text { belajar dengan usia yang berbeda? }\end{array}$ \\
\hline $\begin{array}{l}\text { 2. Bagaimana pengalaman selama ini mengajar } \\
\text { warga belajar mengenal angka dengan permainan } \\
\text { kartu? }\end{array}$ \\
\hline Wawancara warga belajar: \\
\hline $\begin{array}{l}\text { 1. Bagaimana pendapat warga belajar belajar angka } \\
\text { dengan kartu? }\end{array}$ \\
\hline $\begin{array}{l}\text { 2. Bagaimana motivasi untuk belajar angka dengan } \\
\text { bermain kartu? }\end{array}$ \\
\hline
\end{tabular}

Analisis data pada metode kualitatif ini adalah pengumpulan data, reduksi data, penyajian data dan penarikan kesimpulan. Pengumpulan data dilakukan dengan cara melakukan observasi dan wawancara objek penelitian. Reduksi data adalah penyerderhanaan data yang dilakukan melalui seleksi, pemfokusan dan keabsahan data mentah sehingga menjadi informasi yang bermakna dan memudahkan dalam menarik kesimpulan akhir.

Penarikan kesimpulan merupakan tahap akhir dalam analisis data yang dilakukan untuk melihat hasil reduksi data yang mengacu pada rumusan masalah serta tujuan yang hendak dicapai pada penelitian ini. Data yang telah disusun dibandingkan satu dengan yang lainnya sehingga ditarik kesimpulan sebagai jawaban dari rumusan masalah dan tujuan penelitian.

\section{HASIL DAN PEMBAHASAN}

Terdapat dua teknik dalam pengumpulan data pada metode kualitatif ini, yakni teknik observasi dan wawancara. Adapun hasil observasi dan wawancara dari penelitian ini dideskripsikan sebagai berikut.

\section{Observasi}

Pada tahap observasi ini, peneliti ikut berpartisipasi dalam pembelajaran yang dilakukan oleh tutor dengan warga belajarnya. Peneliti mengamati secara langsung proses pembelajaran, mengambil gambar dan mencatat hasil observasi. Tujuan dari observasi partisipatif ini adalah agar peneliti melihat, mengalami dan merasakan secara langsung proses pembelajaran dari awal pembelajaran sampai akhir sesi pembelajaran. Namun disini peneliti hanya sebagai observer dan tidak ikut terlibat dalam proses tersebut.

Dalam proses pembelajaran dengan bermain kartu, tutor menjelaskan materi pembelajaran 
dengan 2 bahasa, bahasa Indonesia dan bahasa daerah. Dari hasil observasi, warga belajar terlihat aktif, termotivasi dan suasana belajar terlihat menyenangkan karena semua warga belajar berpartisipasi dalam penyelesaian instruksi yang diberikan oleh tutor.

Warga belajar mampu mengemukakan pendapat mereka dengan menyampaikan hasil karya masing-masing di depan warga belajar lainnya. Menggunakan strategi ini warga belajar belajar juga mampu bekerjasama dalam kelompok, menyelesaikan instruksi tutor bersama kelompok dan menyimpulkan materi yang diberikan oleh tutor. Dengan bermain kartu, warga belajar mampu memahami materi yang tutor sampaikan dengan bantuan media yang berupa kartu angka.

\section{Wawancara}

Sesi wawancara ini dilakukan terhadap 1 orang tutor dan 4 orang warga belajar sebagai perwakilan dari warga belajar lainnya. Tujuan dari wawancara ini yakni untuk mengetahui bagaimana motivasi mereka setelah belajar angka dengan bermain kartu angka. Wawancara ini dilakukan seperti dialog biasa dan terkesan santai agar informasi yang didapatkan murni dari sudut pandang mereka. Selain itu, peneliti juga melakukan wawancara dengan tutor yang mengajar pada saat observasi lapangan berlangsung. Adapun hasil wawancara dengan objek penelitian dideskripsikan seperti dibawah ini.

\section{Pedoman wawancara warga belajar:}

Pertanyaan pertama: Bagaimana pendapat kalian belajar angka dengan kartu?

Hasil wawancara dengan warga belajar perempuan adalah sebagai berikut:

"belajar angka dengan kartu itu membuat kami memahami materi dengan lebih mudah karena kami langsung melihat angkanya yang besar daripada di buku”.

Hasil wawancara dengan warga belajar lakilaki adalah sebagai berikut:

"belajar angka dengan bermain kartu itu menyenangkan dibandingkan dengan mendengar dan mencatat saja”.

Pertanyaan kedua: Apa kalian merasa termotivasi untuk belajar angka dengan bermain kartu?

Hasil wawancara dengan warga belajar perempuan adalah sebagai berikut:

"Bekerja dalam kelompok juga menyenangkan karena kami saling membantu untuk mengerti angka dan saya suka jika bekerjasama, ada yang membantu".

Hasil wawancara dengan warga belajar lakilaki adalah sebagai berikut:

"Kami senang membuat tugas dan menyelesaikan tugas dengan kelompok. Kami lebih antusias untuk belajar bersama-sama dan saling membantu apalagi belajar dengan media yang menarik. Itu membuat kami lebih mudah untuk mengerti”.

\section{Pedoman wawancara warga tutor:}

Pertanyaan pertama: Sejauh mana efektivitas permainan kartu dalam mengenal angka yang sekaligus memotivasi warga belajar dengan usia yang berbeda?

Pertanyaan kedua: Bagaimana pengalaman selama ini mengajar warga belajar mengenal angka dengan permainan kartu?

Hasil wawancara kepada tutor: "mengajar warga belajar dengan usia berbeda itu menjadi tantangan bagi tutor keaksaraan dasar karena dengan usia yang berbeda tentu cara belajar, 
motivasi dan pengalaman belajar mereka juga berbeda. Mereka memiliki level kemampuan untuk menangkap materi pembelajaran yang berbedabeda pula. Disini saya berusaha mencari strategi pembelajaran yang berbeda dan menarik untuk warga belajar yang berbeda tersebut sehingga mereka akan berpartisipasi untuk menemukan sesuatu dalam proses pembelajaran. Topik pembelajaran mengenal angka ini, cocok dikombinasikan dengan permainan kartu angka. Dengan membuat kartu angka yang lebih besar dari yang ada di buku, warga belajar akan lebih mudah mengidentifikasi angkaangka tersebut. Permainan kartu dalam kelompok ini juga mampu menciptakan suasana pembelajaran yang aktif karena warga belajar akan bekerjasama dalam kelompoknya. Selain itu, dengan kartu angka ini, warga belajar lebih mudah mengidentifikasi antara huruf dan angka sehingga tidak memahami satu bagian saja”.

Dari hasil wawancara dengan warga belajar dan tutor, dapat disimpulkan bahwa belajar angka dengan kartu angka sangat efektif untuk warga belajar keaksaraan fungsional dengan usia yang berbeda. Motivasi dan antusisme belajar warga terlihat dengan belajar bersama warga lainnya, saling membantu untuk memahami pembelajaran.

Hasil penelitian ini berhubungan dengan hasil penelitian penggunaan media kartu angka dalam pembelajaran angka oleh (Annisa \& Dwi, 2019; Mulyasni, 2016; Nurfitriyanti \& Lestari, 2016; Pertiwi, 2019)66 dan thitung $\geq$ ttabel yaitu 48,66 $\geq 1,68$ sehingga $\mathrm{H} 0$ ditolak yang artinya $\mathrm{H} 1$ diterima. Adapun hasil observasi pada pertemuan I menunjukkan bahwa siswa masih kurang memperhatikan penjelasan guru tentang materi, siswa masih melakukan kecurangan pada permainan math games seperti mencabut kartu sebanyak dua kali, masih salah berhitung dalam bermain yaitu disebabkan karena masih kurangnya kemampuan siswa dalam berhitung sehingga menyebabkannya kesulitan dalam menurunkan kartu remi saat gilirannya memberikan kartu dan membutuhkan waktu yang cukup lama dalam bermain (lembar observasi terlampir. Penelitian tersebut menunjukkan adanya pengaruh penggunaan media belajar berupa kartu angka sebagai alat belajar yang inovatif yang mampu merangsang ketertarikan siswa dalam belajar.

\section{PENUTUP}

\section{Simpulan dan Saran}

Penelitian meningkatkan kemampuan keaksaraan dan motivasi belajar warga belajar keaksaraan dasar dengan bermain kartu dapat disimpulkan sebagai berikut.

Strategi pembelajaran bermain kartu dalam belajar angka mampu menumbuhkan motivasi belajar warga belajar. Proses belajar mengajar menjadi lebih menarik, menyenangkan dan memudahkan warga belajar untuk memahami materi yang disampaikan oleh tutor. Menggunakan strategi ini yang diselipkan di akhir pembelajaran sebagai ice breaker mampu mengarahkan warga membuat kesimpulan proses pembelajaran angka yang diikuti.

Penelitian kedepannya disarankan agar lebih mengeksplorasi strategi dan pendekatan andragogi dalam pembelajaran sehingga program pendidikan keaksaraan dasar dapat tepat sasaran dan mencapai target untuk menuntaskan dan memfasilitasi warga negara usia produktif yang masih tergolong buta aksara 


\section{DAFTAR PUSTAKA}

Abiddin, N., Ismail, A., dan Suwirta, A. (2015). "Faktor-faktor yang Membantu dan Menghalangi Pembelajaran Orang Dewasa : Implikasi kepada Pembangunan Sumber Manusia". Jurnal Kajian Pendidikan, 5(1), 23-32.

Andriani, R., dan Rasto, R. (2019). "Motivasi Belajar sebagai Determinan Hasil Belajar Siswa. Jurnal Pendidikan Manajemen Perkantoran, 4(1), 80. https://doi.org/10.17509/jpm. v4i1.14958.

Apriani, F., dan Prakoso, C.T. (2019). Implementasi Program Keaksaraan. 7, 8499-8511.

Annisa B.P. dan Dwi N.N. (2019). "Penggunaan Math Game Kartu Remi Berhitung (Karetung) terhadap Kemampuan Operasi Hitung Siswa". Jurnal Equation, 2 (1), 6078.

Creswell, J., dan Poth, C. (2013). "Qualitative Inquiry Research Design". Dalam Journal of Chemical Information and Modeling (Vol. 53, Issue 9).

Emda, A. (2018). "Kedudukan Motivasi Belajar Siswa dalam Pembelajaran". Lantanida Journal, 5(2), 172. https://doi.org/10.22373/ lj.v5i2.2838.

Hapnita, W. (2018). "Faktor Internal dan Eksternal yang Dominan Mempengaruhi Hasil Belajar Menggambar dengan Perangkat Lunak Siswa Kelas XI Teknik Gambar Bangunan SMKN 1 Padang Tahun 2016/2017". CIVED (Journal of Civil Engineering and Vocational Education), 5(1).

Hayes, D. (2016). "The Value of Learning English in Thailand and Its Impact on Thai: Perspectives from University Students. Asia Pacific Journal of Education, 36(1), 73-91.

Khoriunnisa, A. (2018). Diklus: Jurnal Pendidikan Luar Sekolah, 2(2), September 2018 - 116 Aisyah Khoriunnisa. 2(September), 116131.
King, A. M. (2019). Teaching and Learning in Communication Sciences \& Disorders Speech-Language Pathology Students' Motivation for Learning. 3(1).

Lai, H.T., \& Ting, K. (2013). English Language Learners' Perceptions of Motivational Changes. 6(8), 10-20. https://doi. org/10.5539/elt.v6n8p10.

Mulyasni. (2016). "Permainan Kartu Bilangan sebagai Alat Peraga untuk Meningkatkan Motivasi Belajar Matematika Siswa Kelas V SDN 010 Ujung Batu". Jurnal Primary Program Studi Pendidikan Guru Sekolah Dasar Fakultas Keguruan dan IImu Pendidikan Universitas Riau, 5 (3), 361367; Jurnal Aplikasi IImu-ilmu Agama, 5 (1), $1-13$

Nurfitriyanti, M., dan Lestari, W. (2016). "Penggunaan Alat Peraga Kartu Domino terhadap Hasil Belajar Matematika". Jurnal Kajian Pendidikan Matematika, 01(02), 247-256.

Pane, A., dan Darwis Dasopang, M. (2017). "Belajar dan Pembelajaran". Fitrah:Jurnal Kajian IImu-IImu Keislaman, 3(2), 333. https://doi.org/10.24952/fitrah.v3i2.945.

Pertiwi, A. B. (2019). "Penggunaan Math Game Kartu Remi Berhitung (Karetung) terhadap Kemampuan Operasi Hitung Siswa". Jurnal Equation: Teori dan Penelitian Pendidikan Matematika, 2(1), 60. https:// doi.org/10.29300/equation.v2i1.2312.

Rochman, M., Marjiono, dan Imsiyah, N. (2017). "Faktor-faktor Penyebab Rendahnya Pasrtisipasi Warga Belajar dalam Program Keaksaraan Fungsional di Kelurahan Antirogo, Kecamatan Sumbersari, Kabupaten Jember". Jurnal Pendidikan Luar Sekolah, 1(1), 21-24.

Sadid,A. (2019). "Hubungan Strategi Pembelajaran dan Gaya Kognitif terhadap Hasil Belajar Warga Belajar Kelas IV Paket A Setara SD". Jurnal IImiah Visi, 14(1), 47-58. 
Saputra, H.D., Ismet, F., dan Andrizal, A. (2018). "Pengaruh Motivasi terhadap Hasil Belajar Siswa SMK". Invotek: Jurnal Inovasi Vokasional dan Teknologi, 18(1), 25-30. https://doi.org/10.24036/invotek.v18i1.16.8

Sing, C., Wong, L., King, R.B., Chai, C.S., Wong, L., dan King, R.B. (2016). "International Forum of Educational Technology \& Society Surveying and Modeling Students' Motivation and Learning Strategies for Mobile-Assisted Seamless Chinese Language Learning Surveying and Modeling Students' Motivation and Learning Strategies for Mobile-Assisted Seamless Chinese Language Learning". 19(3), 169180.

Suhud, M.A. (2005). "Pendekatan Andragogi dalam Pengembangan Masyarakat". Aplikasia, VI(1), 1-13. http://digilib.uinsuka.ac.id/8318/1/MOH. ABU SUHUD PENDEKATAN ANDRAGOGI DALAM PENGEMBANGAN MASYARAKAT.pdf.

Sujatmoko, E. (2010). "Hak Warga Negara dalam Memperoleh Pendidikan". Jurnal Konstitusi, 7(1), 181-212.

Syukri, M. (2008). "Pendidikan Keaksaraan Fungsional: Konsep dan Strategi Pengembangan Program". Jurnal Cakrawala Kependidikan, 6(2), 218577.

Vibulphol, J. (2016). 'Students' Motivation and Learning and Teachers' Motivational Strategies in English Classrooms in Thailand". 9(4), 64-75. https://doi. org/10.5539/elt.v9n4p64.

Waspodo, M. (2009). "Peran Tutor dalam Pembelajaran dengan Pendekatan Andragogi". Jurnal IImiah VISI PTK-PNF, 4(1), 63-70.

Wulandari, R. (2018). "Pemberdayaan Aksara Masyarakat Pedesaan : Evaluasi Program Keaksaraan Fungsional pada Kelompok 'Ngudi Kawruh' di Kelurahan Pasar Kliwon, Kota Surakarta". Cendekia : Jurnal
Studi Keislaman, 3(1), 1-10. https://doi. org/10.37348/cendekia.v3i1.34

Yulianingsih, W., dan Pd, M. (2014). Artikel oleh: Handika Putra Pratama Universitas Negeri Surabaya Ngoro Binaan Uptd Skb Gudo Kabupaten Jombang Implementation Of The Base Level In Functional Literacy As The Effort In Increasing Independency Learner Society In Sidowareg Ngoro Guidance By. Diakses dari https://jurnalmahasiswa. unesa.ac.id/index.php/jurnal-pendidikanluar-sekolah/article/view/7615.

Yuse, A. P., Jamaris, J., dan Ismaniar, I. (2018). "Penerapan Pembelajaran Orang Dewasa oleh Instruktur Pelatihan Keterampilan Menjahit di SPNF SKB Lima Puluh Kota". Spektrum: Jurnal Pendidikan Luar Sekolah (PLS), 1(1), 16. https://doi.org/10.24036/ spektrumpls.v1i1.9199.

Zuniarti, Z., dan Siswanto, B.T. (2013). "Pengaruh Motivasi Belajar, Kinerja Intensitas Pembimbingan Prakerin terhadap Kesiapan Kerja Siswa SMK Pariwisata DIY". Jurnal Pendidikan Vokasi, 3(3), 405-415. https:// doi.org/10.21831/jpv.v3i3.1852. 